\title{
STATIC ANALYSIS OF UPLIFT FORCES ON BURRIED FLOATING FOUNDATION AND DIAPHRAGM WALLS*
}

\author{
Ashraf M. El-shihy, Osman E. Shallan, Tarek N. Salem, and Tamer S. Yousif ${ }^{1+}$ \\ Structural Eng. Dept., Faculty of Engineering, Zagazig University, Zagazig, Egypt. \\ ${ }^{1}$ Modern Academy for Engineering \& technology, Maadi, Egypt.
}

\begin{abstract}
Underground facilities are an integral part of the infrastructure of modern society and are used for a wide range of applications, including subways and railways, highways, material storage, sewage and water transport.

This paper presents a study of the behavior of multi-storey building consists of three underground floors and six floors above the ground surface. The computer software ADINA (Automatic Dynamic Incremental Nonlinear Analysis) is used in simulating the static behavior of the multi-storey building with surrounding soil domain. The soil is modeled as Mohr-Coulomb material, whereas the multi-storey building is modeled as elastic material simulating the reinforced concrete material. Many parameters are considered in the analysis, such as; soil type, diaphragm walls thickness and embedment depth through the soil media.

The results indicated that, during the static loading analysis increasing the diaphragm walls widths and embedment depth is not effective in reducing the lateral deformations in case of clay soil. In such case, the stability of the diaphragm walls is achieved using ground anchors support system. On the other hand, increasing the diaphragm wall embedment depth in the dense soil resulted in a noticeable reduction in the lateral deformations. In such case, ground anchors are also used for practical reasons and to account for unexpected loads such as earthquake which may occur during the construction period.
\end{abstract}

KEY WORDS: static; multi-storey building-soil; Mohr-Coulomb; diaphragm walls.

\section{ANALYSE STATIQUE DE FORCES DE SOULEVEMENT SUR LA FONDATION FLOT- TANT ENTERRE ET PAROIS MOULEES}

\section{RÉSUMÉ}

Installations souterraines sont une partie intégrante de l'infrastructure de la société moderne et sont utilisés pour un large éventail d'applications, y compris les métros et voies ferrées, autoroutes, le stockage du matériel, des eaux usées et le transport de l'eau.

Cet article présente une étude sur le comportement de plusieurs étages est composé de trois étages souterrains et six étages au-dessus de la surface du sol. Le logiciel informatique ADINA (automatique dynamique incrémentale Non liner Analysais) est utilisé pour simuler le comportement statique du bâtiment multi-étages avec entourant domaine des sols. Le sol est modélisé comme matériau de Mohr-Coulomb, tandis que le bâtiment de plusieurs étages est modélisée comme un matériau élastique simulant le matériau béton armé. De nombreux paramètres sont pris en compte dans l'analyse, tels que; le type de sol, des murs à membrane épaisseur et la profondeur d'enfoncement du sol à travers les médias.

Les résultats indiquent que, lors de l'analyse statique de chargement augmente les parois moulées largeurs et profondeur d'ancrage n'est pas efficace dans la réduction des déformations latérales dans le cas d'un sol argileux. Dans un tel cas, la stabilité de la paroi moulée est réalisée en utilisant le système d'appui au sol ancres. D'autre part, l'augmentation de la profondeur d'ancrage paroi moulée dans le sol dense a entraîné une réduction notable dans les déformations latérales. Dans un tel cas, les ancrages au sol sont également utilisés pour des raisons pratiques et pour tenir compte des charges inattendues telles que tremblement de terre qui peuvent se produire pendant la période de construction.

MOTS-CLES: statique; multi-étages-sol; Mohr-Coulomb; parois moulées.

* Received: 26/6/2011, Accepted: 24/8/2011, (Original Paper)

+ Contact Author (+20 101626881) 


\section{INTRODUCTION}

The number of deep excavation pits in any city center is increasing every year. Buildings, streets surrounding excavation locations and design of very deep basements make excavations formidable projects. Diaphragm walls provide structural support and water tightness. It is a classical technique for many deep excavation projects, large civil engineering works, underground car parks, metro pits etc. especially underground water table. Diaphragm walls supported by ground anchors are given more emphasis compared to others due to widespread use observed in the recent years [2].

In the static analysis, the structure and soil behaviors depend on the interaction between them. The structure may be represented by a specific number of degree of freedom, but the soil domain has theoretically infinite dimension. Therefore, the largest possible size of the soil domain underneath the structure should be considered due to the huge stiffness difference between them, especially when performing dynamic analysis in the model. On the other hand, increasing the soil domain size will consequently need elaborate modelling and analysis effort. In addition to the structure and the underlying soil, the interface between the structure and soil needs special treatment [6].

Numerical analysis has become an essential tool in investigating the soil structure interaction problems. One of the most powerful and versatile numerical analysis tools is the finite element method. It is capable of representing the struc- ture, soil nonlinearity, non-homogeneity, and different soil layer and damping properties [6].

The in-hand problem is the static analysis of uplift forces on buried foundations and diaphragm walls. Underground basements are subjected to lateral earth and water pressures, in addition to the uplift water pressure on their raft foundations. The static behavior of such underground basements, surrounding soils, along with the structure itself is presented in this paper. Fig. 1 illustrates a typical soil problem showing a structure, with finite dimensions, embedded in a deformable soil of finite dimensions.

In this mode, the side boundaries are represented by rollers, whereas the interface between the soil domain the diaphragm walls and raft foundation is modeled using special interface element accounting for the diaphragm wall friction.

Thus, the main objectives of this paper include:

- Studying the effect of the uplift water pressure on the raft foundation supported with diaphragm walls.

- Studying the lateral deformations of the diaphragm walls including the effect of embedment depth and thickness with and without ground anchors system support in both types of soil; sand and clay soils.

- Studying the interaction between the soil and structure components.

- Studying the settlements, effective stresses, and pore water pressures within the soil domain.

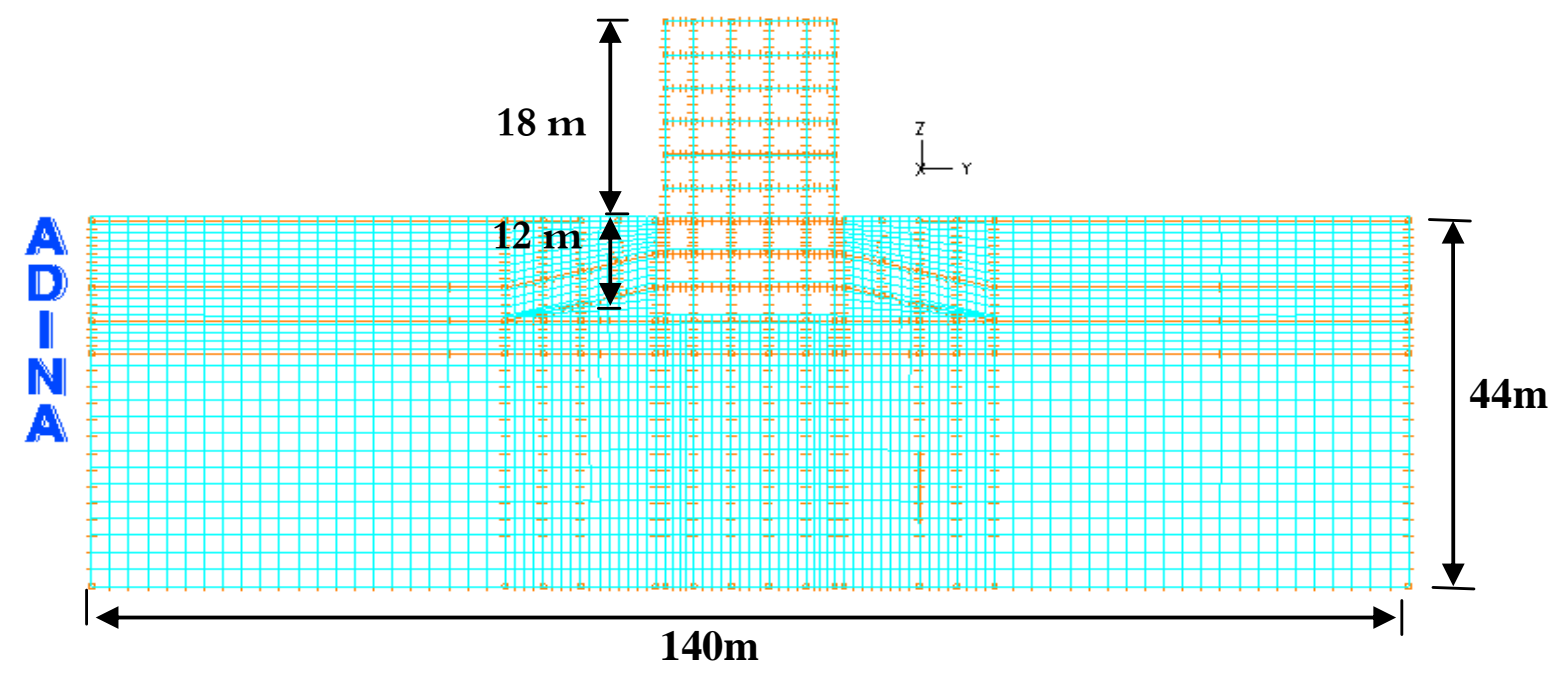

Fig. 1: Problem definition of soil structure interaction 
Finite Element (FE) method is one of the most powerful numerical techniques available today for the analysis of complex structural and mechanical systems. It is also proposed by several codes as an acceptable method of structural analysis.

\section{MODEL ASSUMPTIONS}

Analysis of uplift forces on buried foundation and diaphragm walls model is analyzed in two stages:

Analysis Stage I: In this loading stage the soil is allowed to consolidate under its own weight, till the excess pore water pressure fully dissipates, indicating the end of the consolidation stage.

Analysis Stage II: In this stage the diaphragm walls are constructed, the excavation is performed in the zone bounded by the diaphragm walls, the raft is then constructed. In this stage, the diaphragm walls are constructed with and without ground anchors.

\section{NUMERICAL MODELS}

The diaphragm walls dimensions, raft foundation and surrounding soil domain is modeled as plane strain. The finite element model, as presented in ADINA software is shown in Fig. 1. The diaphragm walls and the raft foundation are modeled with 2-node beam element with 2 displacement degrees of freedom at each node. The properties of the reinforced concrete are assigned the following values:

$$
\begin{aligned}
& \text { Elastic modulus }(E)=2.09 \times 10^{7} \mathrm{MPa} \\
& \text { Poisson's ratio }(v)=0.25 \\
& \text { Density of concrete }(\gamma)=25.0 \mathrm{kN} / \mathrm{m}^{3} .
\end{aligned}
$$

The anchors are modeled with 2-node truss element with 2 displacement degrees of freedom at each node. The properties of the reinforced concrete are assigned as the above values of the diaphragms and footing of the structure.

The finite element mesh of the in-hand problem is shown in Fig. 1. The soil is modeled using 4-node plane strain element with 2 displacement degrees of freedom at each node. In addition an extra fluid pressure node is added at each corner node to account for the effect of presence of water within the saturated soil media. The overall dimensions are $140 \mathrm{~m}$ width with $44 \mathrm{~m}$ depth and extend to a great length in the perpendicular direction, allowing the soil to be modeled as plane strain. It is assumed that just one soil layer of uniform soil properties exist throughout the mesh. The soil prosperities of each case are presented in Table 1 .

3.1 Mohr-Coulomb Formulation: The MohrCoulomb model is used in Soil Structure Interaction (SSI) finite element models efficiently and simply to characterize the non-linear behavior of the soil under static or dynamic condition. The model is a two parameter model, mainly characterized by the well known soil shear strength parameters (c and $\phi)$, in addition to other well known soil parameters, like the soil modulus (E), and the Poisson's ratio (v). Soil angle of dilation $(\psi)$ can be fed to the program considering a non-associated flow rule [1].

It should be noted that some advanced soil models have something like twenty parameters or so. Despite being very accurate when modelling the original problems they were calibrated for, these models usually fail in modelling any other geotechnical problem for simple reasons. First, the large number of model parameters rendered the model much complexity increasing the chance of errors in modelling. In addition, the real meaning of these parameters is not usually comprehended, even for simpler models like the Cam-Clay model [6].

3.2 Porous Media Formulation: The porous domain consists of both fluid and solid. The formulation of the porous media is applicable to porous structures subject to static or dynamic loading. It deals with the interaction between the porous solids and pore fluids, which flow through the porous solid skeleton as prospected in Fig. 2. In this study, a 2D plane strain solid element with 4-nodes, and displacement degrees of freedom at each node is used in the analysis. These elements have extra pore pressure nodes at their corner points [1].

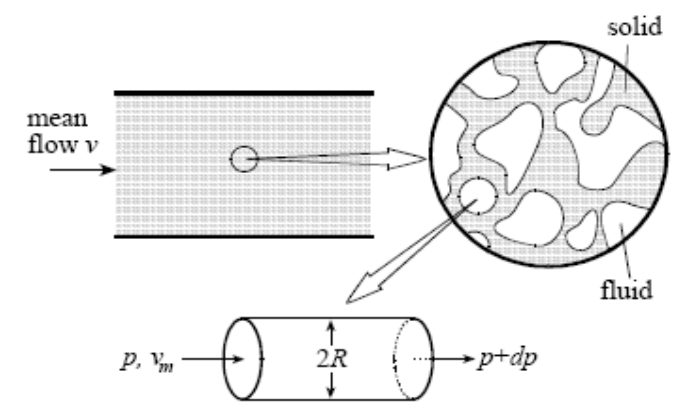

Fig. 2: Illustration of porous media models. 
Static Analysis of Uplift Forces On Burried Floating Foundation and Diaphragm Walls

El-shihy, Shallan, Salem, and Yousif

Table 1: Properties of clay soil used.

\begin{tabular}{|c|c|c|c|c|c|}
\hline Soil Type & $\begin{array}{c}\text { Density of } \\
\text { soil } \rho \\
\left(\mathrm{kN} / \mathrm{m}^{3}\right)\end{array}$ & $\begin{array}{c}\text { Cohesion, } \\
\mathrm{C}(\mathrm{KPa})\end{array}$ & $\begin{array}{c}\text { Angle of inter- } \\
\text { nal friction }\left(\phi^{\mathrm{o}}\right)\end{array}$ & $\begin{array}{c}\text { Compressive } \\
\text { modulus E } \\
(\mathrm{MPa})\end{array}$ & $\begin{array}{c}\text { Angle of Di- } \\
\text { lation }\left(\boldsymbol{\psi}^{\circ}\right)\end{array}$ \\
\hline Medium stiff clay & 17.0 & $\mathrm{C}_{\mathrm{u}}=50.0$ & $\phi_{\mathrm{u}}=0.0$ & 6.0 & 0.0 \\
\hline Dense sand & 18.0 & 0.0 & 38.0 & 80.0 & 8.0 \\
\hline
\end{tabular}

3.3 Linear Elastic Material Models: The linear isotropic material model is used to model the concrete in this research. These models are found in two material models; elastic-isotropic (isotropic linear elastic) and elastic-orthotropic (orthotropic linear elastic). These models can be employed using the small displacement or large displacement formulations. In all cases, the strains are assumed to remain small. When the elastic-isotropic and elastic-orthotropic materials are used with the small displacement formulation, the formulation is linear and when used with large displacement analysis, the total or the updated Lagrangian formulation is automatically selected by the program depending on which formulation is numerically more effective [1].

In the small displacement formulation, the stress-strain relationship is:

$$
{ }_{0}^{t} \sigma=C_{0}^{t} e
$$

where: ${ }_{0}^{t} \sigma$ : engineering stresses, ${ }_{0}^{t} e$ : engineering strains.

While the total Lagrangian formulation, the stress-strain relationship is:

$$
{ }_{0}^{t} S=C_{0}^{t} \varepsilon
$$

In which: ${ }_{0}^{t} S$ : second Piola-Kirchhoff

stresses, ${ }_{0} \varepsilon$ : Green- Lagrange strains.

In the updated Lagrangian formulation, the stress-strain relationship is:

$$
{ }^{t} \tau=C_{t}^{t}{ }^{a}{ }^{a}
$$

Where: ${ }^{t} \tau$ : Cauchy stresses, ${ }_{t}^{t} \varepsilon^{a}$ : Almansi strains.

The same matrix $\mathbf{C}$ is employed in all of these formulations. As long as the strains are small (with large displacements), the difference in the response predictions obtained with the total and updated Lagrangian formulations is negligible.
However, if the strains are large, the difference in the response predictions is very significant and it is recommended that the linear elastic material model not be used.

3.4 Soil-Structure Interface: Evaluating the interaction of the soil-structure system subjected to a static load is an important step in any static analysis. One of the most important problems in this sort of analysis is the local nonlinear behavior of the interface between the soil and the structure foundations and diaphragm walls. The contact surface approach is used to model soilstructure interface where the nodes of the two surfaces are defined relative to each other by friction coefficient between the surfaces.

\section{STAGES OF ANALYSIS}

4-STEP modelling of the diaphragm walls is performed in ADINA program: First the soil is left to consolidate under its own weight. It would take a long period of time to allow for the generated excess pore water pressure to fully dissipate. It should be noted that the generation and dissipation of excess pore water pressure plays a major role in studying the behavior of soil under static and dynamic loads. Full dissipation of pore water pressure is allowed to take place before starting the construction stages of the diaphragm walls as shown in Fig. 3.

Construction of the diaphragm walls are considered the second stage after ensuring that the soil fully consolidated. After constructing the diaphragm walls, many parameters are considered such as lateral displacement, settlements, vertical stress, and the generated excess pore water pressure that take place in the soil domain, as shown in Fig. 4.

In the third stage, excavation of the zone bounded by the diaphragm walls is performed in stages to allow for the construction of ground anchors. It should be noted that the excavation 
depth is performed in three stages of $4.00 \mathrm{~m}$ each to a total excavation depth of $12.0 \mathrm{~m}$, as shown in Figs. 5 through 7. Fig. 6 shows the construction of the first row of ground anchors followed by the excavation down to $8.00 \mathrm{~m}$. Moreover, Fig. 7 shows the construction of the second row of ground anchors followed by continuing the soil excavation down to $-12.00 \mathrm{~m}$. The construction of raft foundation is then performed as presented in Fig. 8.

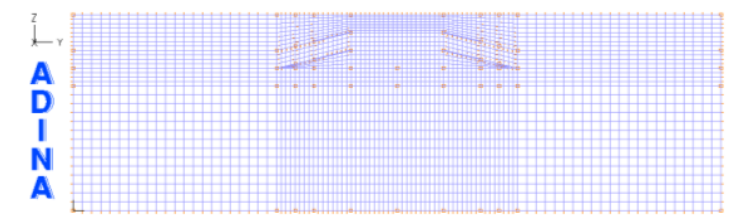

Fig. 3: Modelling of soil domain at start of the loading pattern.

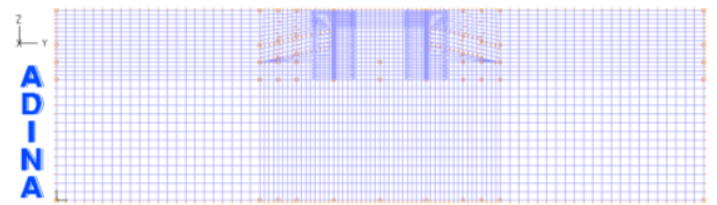

Fig. 4: Modelling of diaphragm walls embedded in soil domain with contact surface.

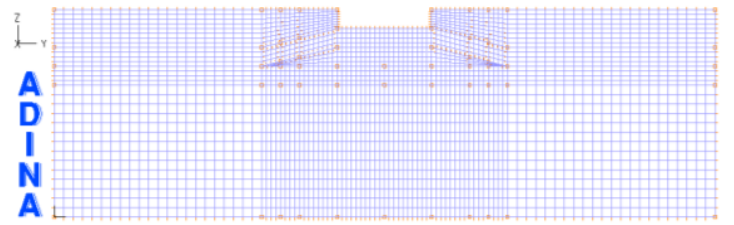

Fig. 5: Start of soil excavation inside the diaphragm walls down to $-4.00 \mathrm{~m}$.

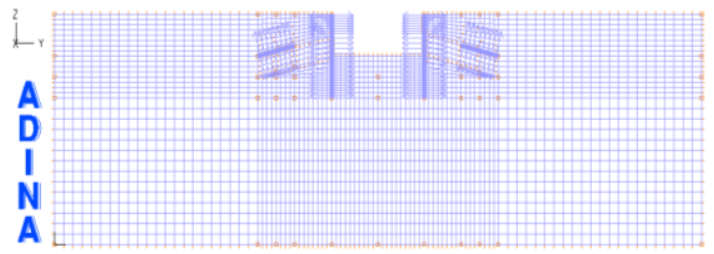

Fig. 6: Construction of first row of anchors along the diaphragm walls.

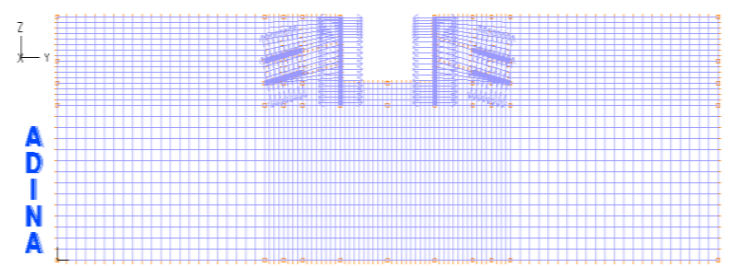

Fig. 7: Construction of second row of the anchor along the diaphragm walls.

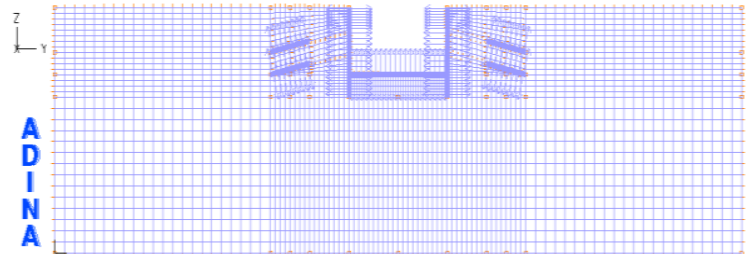

Fig. 8: Construction of raft foundation (final step).

\section{PARAMETRIC STUDY}

To monitor the soil domain behavior during the different construction phases, five points are mainly observed within the soil domain under the raft footing and within the diaphragm walls. These points are mainly used to investigate the effect of many parameters such as; vertical stresses, pore water pressure, vertical displacements (settlements), and horizontal displacements (lateral deformations). The chosen points, shown in Fig. 9 are; Point (A) located at the ground surface to monitor the investigated parameters at the top of the diaphragm walls. On the other hand, Point (B) is chosen under the diaphragm walls to monitor the stresses, pore water pressures, and displacements at this region. In the meantime, Point (C) is located within the soil domain just at the connection between the raft footing and the diaphragm wall to monitor the above mentioned parameters within this region. For the sake of completeness, Point (D) is chosen at the middle of the raft footing to monitor changes of the above parameters under the structure foundations. Moreover, an extra point (Point E) is added just behind the anchor end point to account for the soil behavior at this zone.

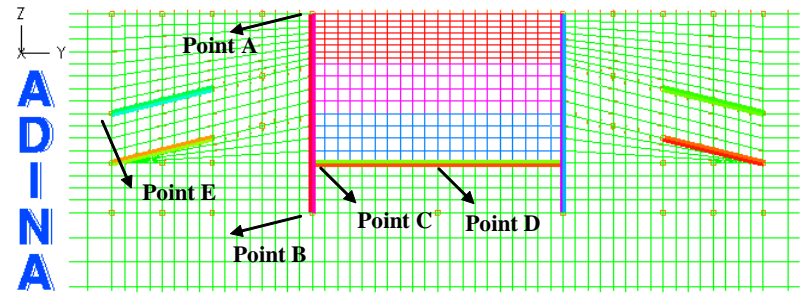

Fig. 9: Location of points (A), (B), (C) and (D) on soil domain chosen for the purpose of analysis. 


\section{ANALYSIS OF RESULTS}

\subsection{Consolidation Stage}

Stresses and pore water pressure contours allover the soil domain are illustrated to represent the effect of the own weight on the soil domain and show the full consolidation of the both types of soil, medium stiff clay soil and dense sand soil. Figs. 10a and $10 \mathrm{~b}$ illustrate settlements within the soil domain. According to the fact that the soil layers exist several centuries and reached the final state of consolidation under its own weight, which appears nowadays. Thus, for a general purpose software as ADINA, the program has to model the consolidation under soil own weight first, and this stage is termed the consolidation stage. In case of medium stiff clay soil the computed maximum settlements reached to $1.20 \mathrm{~m}$, however in dense sand soil the settlements are only $7 \mathrm{~cm}$. The large difference in settlement is mainly due to the consolidation process which took place in clay along with the large difference between soil modulus of the sand and clay soils.

Figs. 11a and $11 \mathrm{~b}$ show the distribution of vertical stresses along the soil domain for the two types of soil. The values obtained from the graph are approximately equal to the overburden pressure.

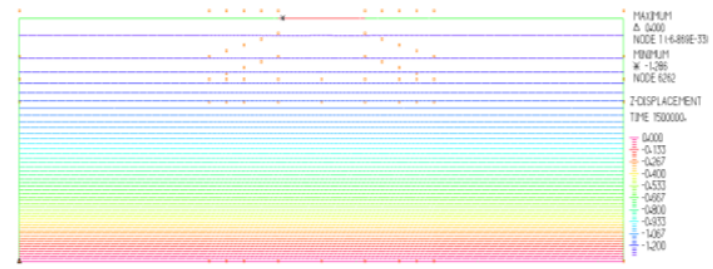

Fig. 10a: Contours of settlement generated in the soil domain due to own weight of the soil for medium stiff clay.

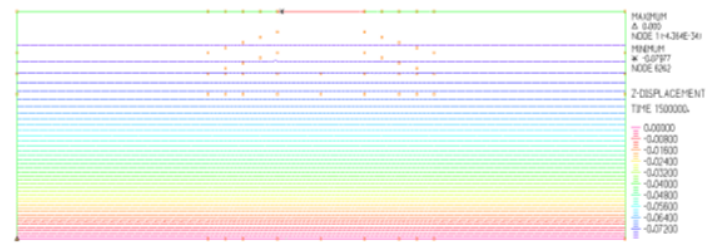

Fig. 10b: Contours of soil settlements generated in the soil domain due to own weight of the soil for dense sand.

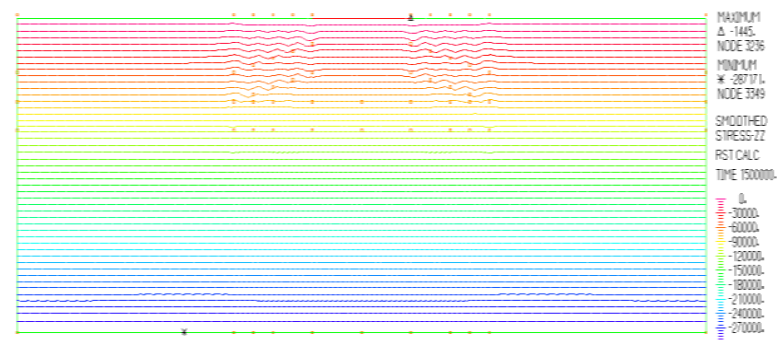

Fig. 11a: Contours of vertical stress generated in the soil domain due to own weight of the soil for medium stiff clay.

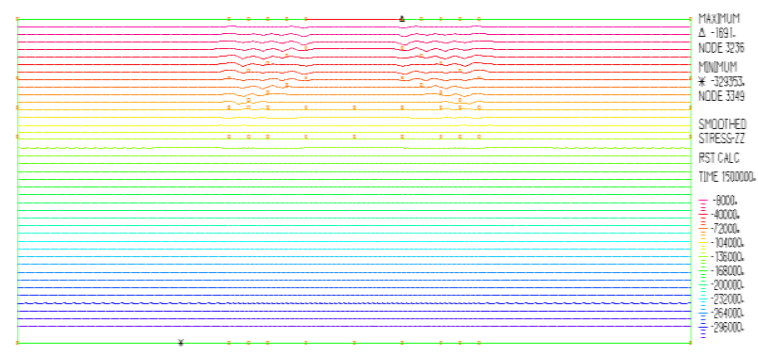

Fig. 11b: Contours of vertical stress generated in the soil domain due to own weight of the soil for dense sand.

The distribution of settlements (vertical displacement) and generated pore water pressures with the time domain of the static stage are presented in Figs. 12 through 15.

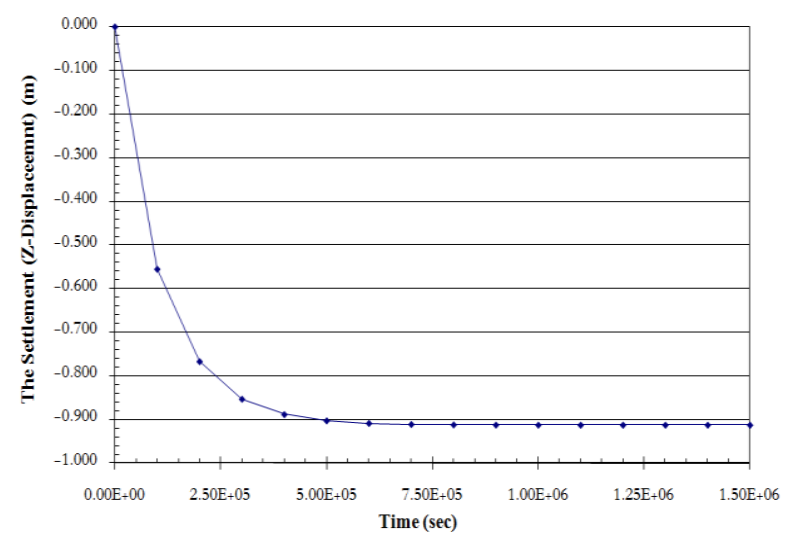

Fig. 12: Variation of settlements with time of static loading pattern for medium stiff clay. 


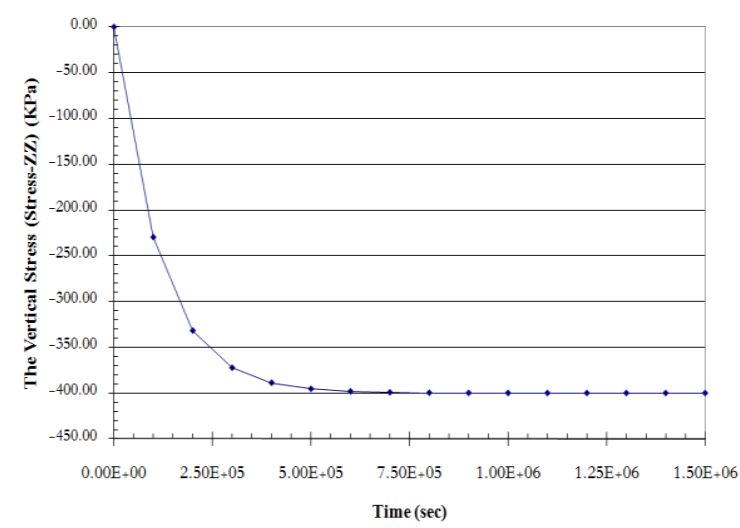

Fig. 13: Variation of vertical stresses with time for static loading pattern for medium stiff clay.

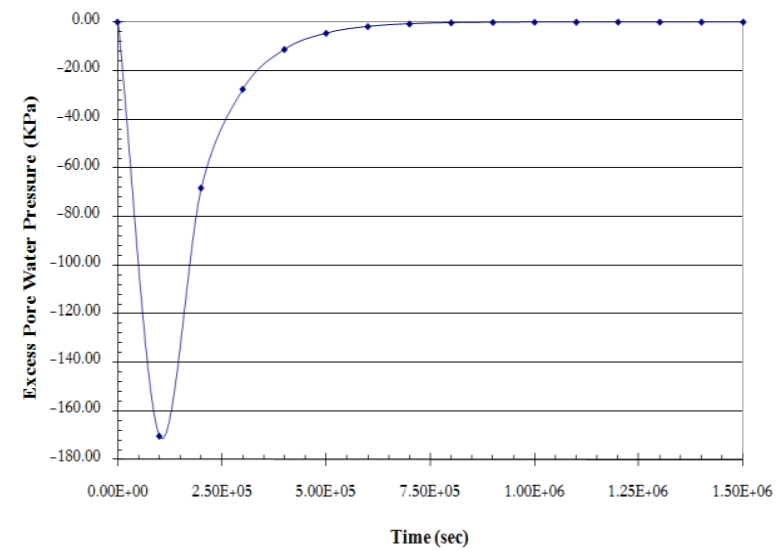

Fig. 14: Excess pore water pressure generated with time for static loading pattern for medium stiff clay.

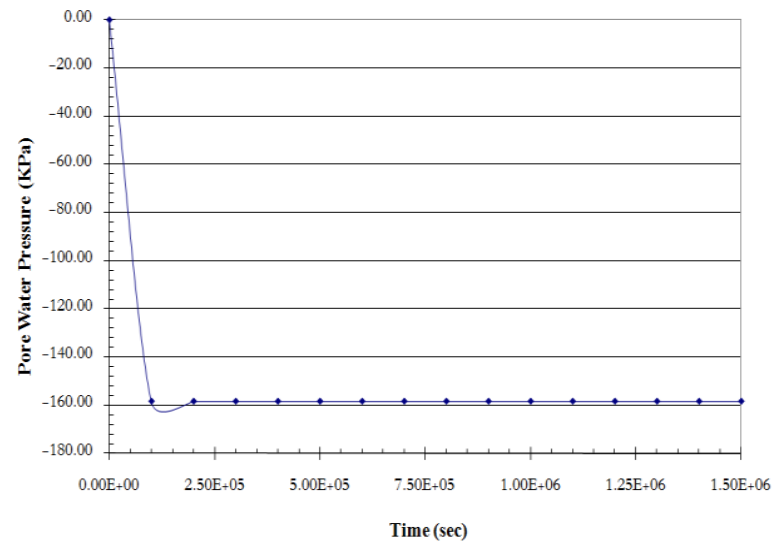

Fig. 15: Pore water pressure generated with time for static loading pattern for medium stiff clay.

\subsection{Construction of the Diaphragm Walls and Raft Foundation}

Construction of the diaphragm wall starts after full consolidation of the soil domain took place, as presented previously. At that time, excavation of the soil between the diaphragm walls starts. Such condition is considered the worst case due to the diaphragm wall lateral movements that takes place due to both lateral earth and water pressures. Such lateral movement may be large enough to cause failure of the diaphragm walls. In the forthcoming sections, a discussion of the calculated diaphragm wall lateral movement and the suggested procedures to overcome it, along with a parametric study is presented.

\subsubsection{Diaphragm wall construction in me- dium stiff clay}

The behavior of diaphragm walls constructed in medium stiff clay soil is studied first. The lateral movement, which is the most critical component at this stage, is closely observed before proceeding in studying other parameters. Fig. 16 shows contours of the lateral movements over the whole model. The maximum lateral movement occurs at the top of the diaphragm walls with values over $10 \mathrm{~cm}$ which means that the diaphragm walls are actually failed, considering a reference lateral movement of $5 \%$ of the diaphragm wall width as a failure [5]. Thus, suggested techniques to enhance the stability of the diaphragm walls in addition to reducing the lateral movement values will be presented in the forthcoming sections.

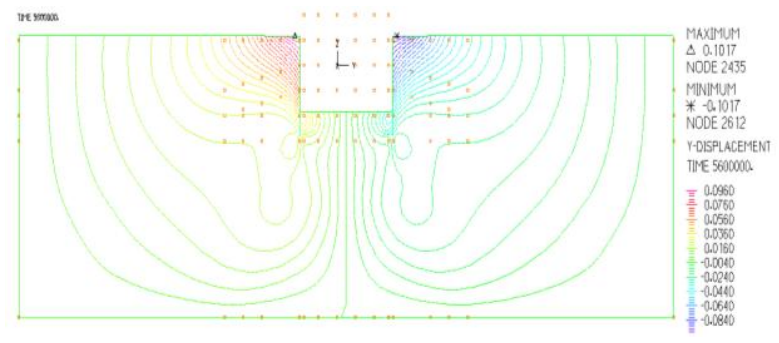

Fig. 16: Contours of lateral displacements within the whole model for a diaphragm wall thickness of $0.60 \mathrm{~m}$. 


\subsubsection{Parameters affecting diaphragm wall stability in stiff clay}

The two parameters which can actually reduce the large lateral movement of the diaphragm walls are mainly the diaphragm wall thickness and embedment depth through the soil media. Each parameter will be separately discussed, along with its effect in the wall lateral movement as follow:

\section{i. Effect of diaphragm wall thickness}

The suitable width of the diaphragm wall is the minimum width that minimizes the lateral wall movement. In this case, five widths are chosen to be studied, while focusing mainly in the lateral movement. These widths are; 0.60, $0.80,1.00,1.20$ and $1.40 \mathrm{~m}$ respectively.

Fig. 17 shows contours of lateral movements within the soil domain for a diaphragm wall thickness of $0.80 \mathrm{~m}$. The calculated maximum lateral movement is $10.17 \mathrm{~cm}$, which could be considered failure, when compared to the allowable 5\% wall width criteria. Although the rigidity of the diaphragm wall is actually increased, the lateral displacement at the wall uppermost point is still large enough to be considered failure, as shown in Fig. 17.

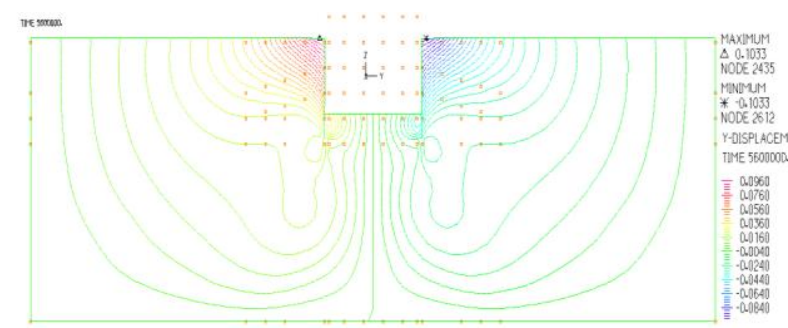

Fig. 17: Contours of lateral displacements within the whole model for a diaphragm wall thickness of $0.80 \mathrm{~m}$.

Fig. 18 illustrates variation of the maximum calculated lateral movement with the diaphragm walls thickness measured at the wall uppermost point. The thickness of the diaphragm wall is increased to $1.00 \mathrm{~m}$ and $1.40 \mathrm{~m}$ in a trial to decrease the lateral displacements. It should be noted that increasing the diaphragm wall thickness resulted in an increase in the wall rigidity, which resulted in larger lateral displacements due to reducing the lateral deformations within the diaphragm wall own body.

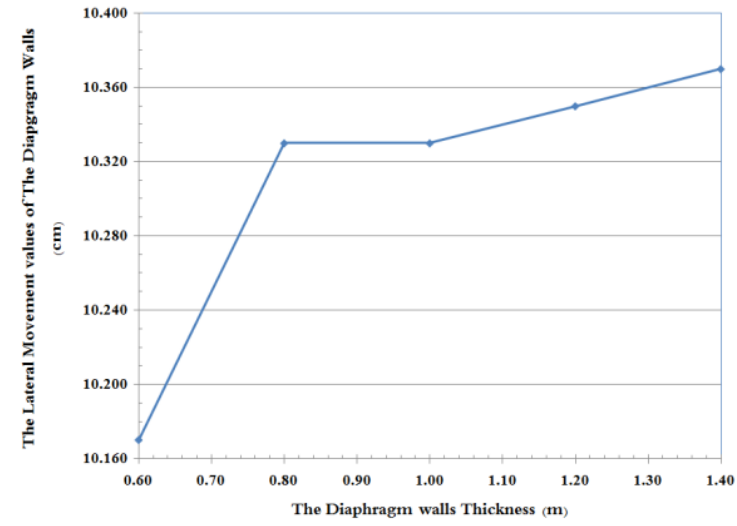

Fig. 18: Effect of increasing the diaphragm wall thickness on the computed maximum lateral movements.

Based on the above Fig., increasing the diaphragm wall thickness did not reduce the lateral displacements but rather resulted in a slight increase in these values. Therefore, the effort will now be directed towards increasing the wall embedment depth to reduce the lateral deformations.

\section{ii. Effect of diaphragm wall embedment depth}

The diaphragm wall embedment depth within the clay soil media is chosen to be $4.00 \mathrm{~m}, 6.00$ $\mathrm{m}$, and $8.00 \mathrm{~m}$ respectively. Contours of lateral displacements are drawn allover the soil domain showing also distribution of the diaphragm wall lateral deformations. Fig. 19 shows that at a diaphragm wall embedment depth of $4.00 \mathrm{~m}$, the maximum lateral displacement occur at the top of the diaphragm walls body, and is equal to $10.33 \mathrm{~cm}$. Increasing the embedment depth to $6.00 \mathrm{~m}$ resulted in increasing the lateral displacements to $10.69 \mathrm{~cm}$ as shown in Fig. 20 . Moreover, increasing the diaphragm wall embedment depth to $8.00 \mathrm{~m}$ resulted also an increase in the lateral deformations to become $11.06 \mathrm{~cm}$, as shown in Fig. 20. These results mean that increasing the embedment depth of the diaphragm walls through the clay soil media resulted in an increase in the lateral wall movement. This may be attributed to the increase in the wall rigidity led to stiffer wall, which in turn act more as one unit. On the other hand, increasing the embedment depth within a clay layer does not mean reducing the lateral wall deformation due to the fact that the active and passive earth pressure coefficients are approximately the same. The effect of clay cohesion in reducing 
the active earth pressure and increasing the passive earth pressure is not that effective, as presented in many local and international codes [3] and [4].

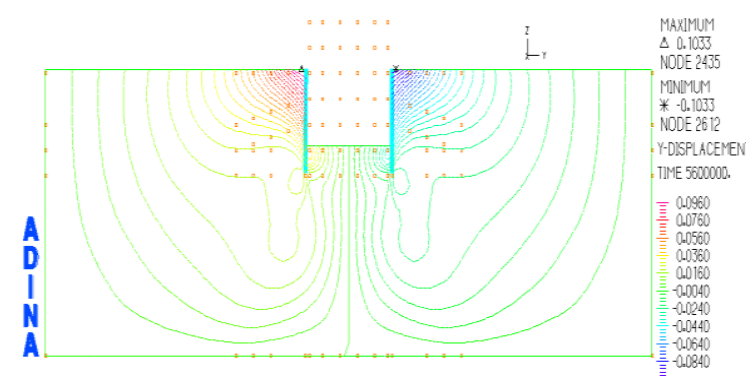

Fig. 19: Lateral displacement occur in the body of the diaphragm wall due to using embedment depth equal to $4.00 \mathrm{~m}$.

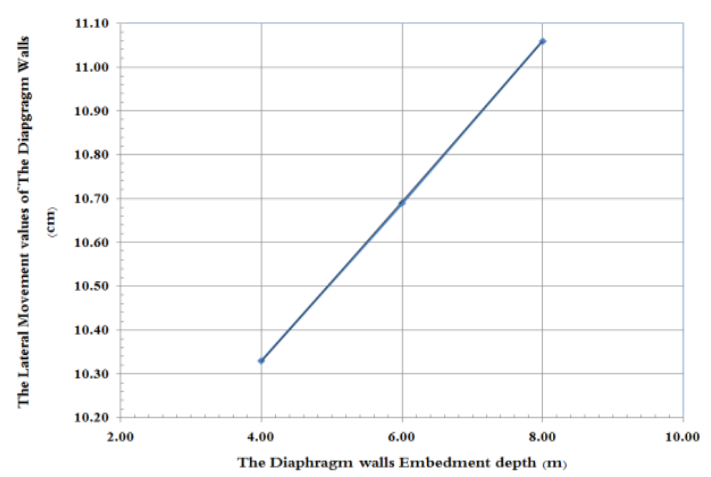

Fig. 20: Values of lateral movement of the diaphragm walls with respect to the increase in diaphragm walls embedment depth.

\subsubsection{Diaphragm wall construction using ground anchors systems}

Ground anchors are used to reduce the lateral displacement values that took place at the diaphragm walls due to the large earth and water pressures acting on such walls. The construction sequence presented previously is applied herein to reduce the lateral diaphragm wall movements. Two anchor rows, specifically at -4.00 $\mathrm{m}$ and -8.00 from the ground surface. It should be noted that the chosen vertical anchor coverage length of $4.00 \mathrm{~m}$ is typically used in practice.

Fig. 21 illustrates that the use of a system of anchors in medium stiff clay soil reduced the lateral displacement that took place within the diaphragm walls body to acceptable values. For a diaphragm wall thickness of $1.00 \mathrm{~m}$ and an embedment depth of $4.00 \mathrm{~m}$, the induced maxi- mum lateral displacement is reduced to 4.50 $\mathrm{mm}$, which is considered an acceptable value. As the lateral displacements lie within the acceptable values, other parameters such as the wall vertical displacements, raft movements, soil settlements, soil stresses, along with the generated pore water pressure within the soil domain will be separately discussed.

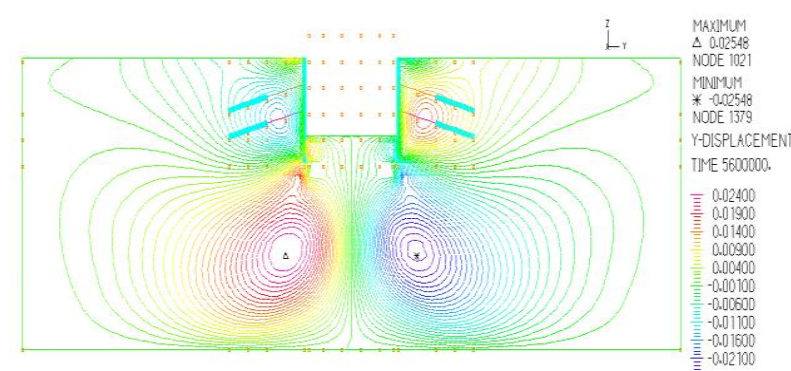

Fig. 21: Lateral displacements generated on the diaphragm wall body and along the soil domain, using system of anchors, for a wall width of $1.00 \mathrm{~m}$, and embedment depth of $4.00 \mathrm{~m}$.

\section{iii. Effect of using ground anchor systems within the soil domain}

The diaphragm wall movement was observed before and after installing the ground anchor systems. Before using the anchor systems the maximum lateral movement of the diaphragm walls reached to $10.77 \mathrm{~cm}$, which in practice means failure. However, after using the anchor system the lateral movements are largely controlled, and became about $7.50 \mathrm{~mm}$, as a maximum value, as shown in Fig. 22. Thus, using the ground anchors lateral support system resulted in stabilizing the diaphragm wall laterally.

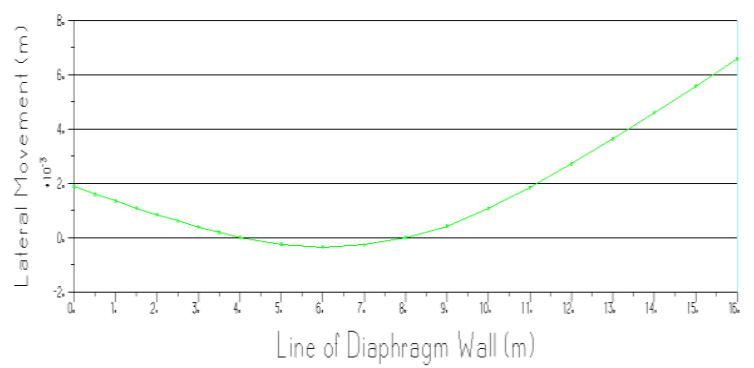

Fig. 22: Final diaphragm walls movement during the static loading pattern in case of using system of anchors. 


\section{iv. Deformations within the raft foundation}

One of the important steps for the design of underground structures is the raft foundation analysis, accounting for the deformations and stresses within the raft foundations under the static loading pattern. These stresses and deformations are observed during the various stages of the model construction sequence.

Under the raft own weight only, the calculated maximum deformations within the reinforced concrete raft body is about $4.0 \mathrm{~mm}$, as shown in Fig. 23. However, a theoretical case of releasing the dewatering system just after the raft completion showed a central upward movement of about $6.0 \mathrm{~mm}$, giving a total of about 10.0 due to the sudden release of the upward groundwater pressure. In fact, this case could not be practically allowed, but may occur due to malfunction in the dewatering system and introduced herein for the sake of presentation. Moreover, adding the structure own weight on the basis of one storey at a time, and still allowing for the upward water pressure is presented also in Fig. 23. The studied cases showed that after completing the fourth floor concrete structure only, the weight of the raft foundation and structure began to compensate the uplift water pressure. Adding more dead loads (stories) resulted in more pronounced sagging (settlement) within the reinforced concrete raft body.

However, during the various construction stages of the structure, the settlements under the raft foundation increase steadily, as shown in Fig. 24. The maximum calculated soil settlement under the raft reaches about $126 \mathrm{~mm}$ after the completing structure skeleton.

The case presented in Fig. 24 is presented in Fig. 25 but showing the soil upward and downward movements due to the release of upward water pressure for each storey added. The figure shows that the total dead load of the structure is approximately compensated by the uplift water pressure caused by ceasing the dewatering system.

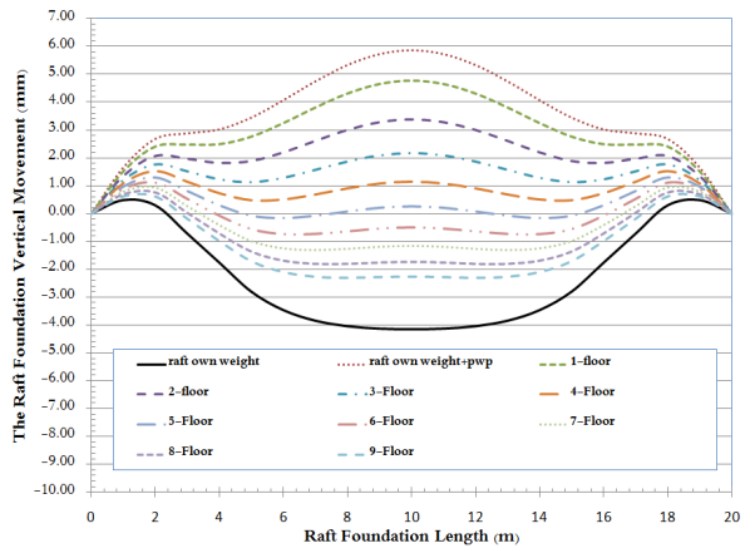

Fig. 23: Vertical raft foundation movement with respect to presence of pore water pressure on the raft foundation after construction each cases.

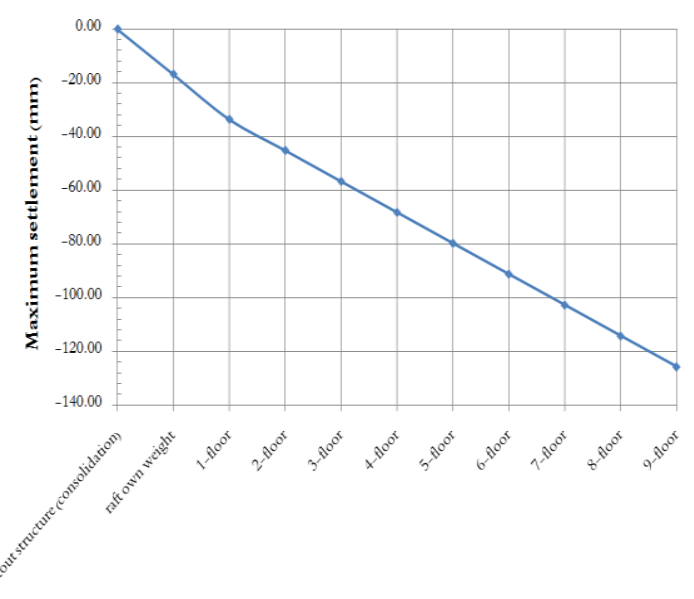

Fig. 24: Calculated maximum settlement for a random node under the raft foundation in different cases of loading in the case of dewatering systems.

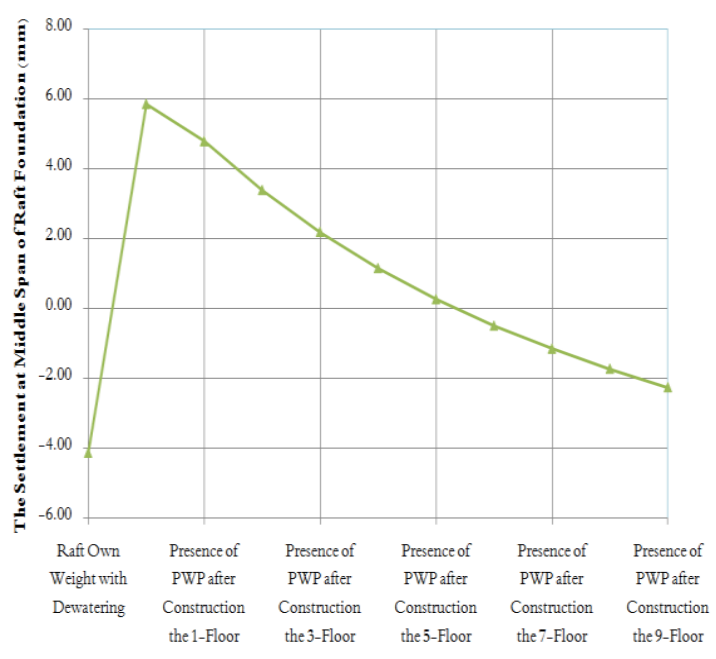

Fig. 25: Total soil settlement under the raft for sequential floor loading. 
6.2.2 Diaphragm wall construction in dense sand soil

Another soil type is studied in this case. The diaphragm wall body is constructed in dense sand, with a thickness of $1.00 \mathrm{~m}$ and embedment depth of $4.00 \mathrm{~m}$ without using any lateral support system, i.e., no ground anchors are used in this case.

Fig. 26 presents contour line distribution of lateral displacements within the soil domain, at the end of the static loading pattern after completion of the diaphragm wall construction and the raft foundations. In the case of dense sand, higher passive earth pressures are generated in front of the diaphragm wall embedment resisting the lateral active earth and water pressures. These generated passive earth pressures are large enough to virtually keep the diaphragm wall vertically with slight acceptable lateral deformations. The maximum recorded lateral wall displacement was about $7.00 \mathrm{~mm}$, as shown in Fig. 26.

Although the calculated lateral displacements are reasonable and lies within the accepted range, the practice dictates the use of lateral support system for such relatively large excavation depth.

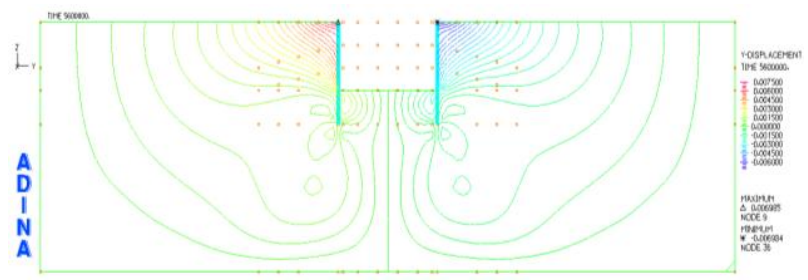

Fig. 26: Distribution of the lateral displacement along the whole dense sand soil in case of using diaphragm walls without supported by anchors systems represented by contours line.

6.2.2.1 Lateral Displacements in Case of Diaphragm Walls Supported by Anchor Systems:

The lateral deformations that took place within the whole model using the anchorage system will be much less than the calculated values without any lateral support system, due to the presence of extra lateral support points which in turn will reduce the previously calculated values. Fig. 27 illustrates the lateral displacements occurring all-over the whole soil domain at the final static loading pattern, in which the calculated lateral displacements at the diaphragm wall uppermost point was about $0.1 \mathrm{~mm}$. This calculated value actually means that there are no lateral movements for such case.

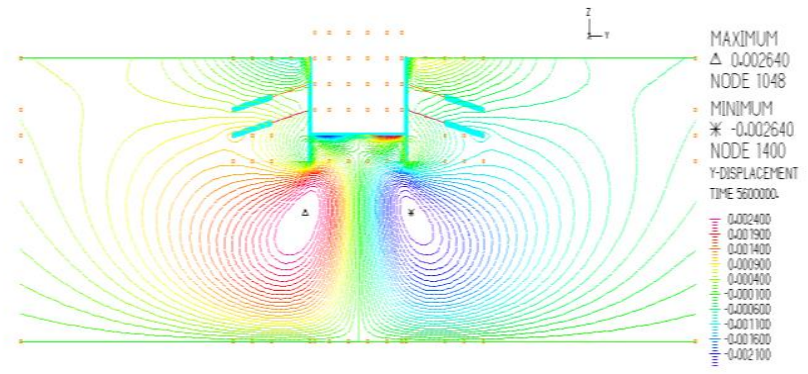

Fig. 27: Lateral displacement (YDisplacement) produced in the body of the diaphragm walls supported by system of anchors through static loading pattern.

\section{CONCLUSIONS}

Based on the results of this study, the following conclusions are drawn:

i. Relatively large and unacceptable lateral deformations took place due to the lateral earth and water pressures in the diaphragm walls during the construction phase, which reached about $13 \%$ of the diaphragm wall thickness. Increasing the diaphragm wall width and embedment depth does not reduce such lateral deformations into the acceptable range. Thus, ground anchors are necessarily used in such soil conditions due to the relatively deep foundation level.

ii. The lateral deformations that took place in the diaphragm walls in dense sand are relatively small and are within the acceptable limits, about $1.20 \%$ of the diaphragm wall thickness. However, in practice ground anchors should also be used in such deep excavation.

iii. Ground anchors along with the raft foundations and friction between the diaphragm walls and surrounding soils could actively resist the uplift water pressure on the closed box formed by the diaphragm walls and the raft foundation. In such case, the computed maximum heave differential movement was about 1:1500. Moreover, adding the floor loads consequently reduced the slight heave that took place in the raft foundation into downward settlement again. 


\section{REFERENCES}

1. Bathe, K.J., (2011), "ADINA/Standard User's Manual, Version 8.7.3", Watertown, USA.

2. Ergun, M.U., (2001), "Deep Excavation" Department of Civil Engineering, Middle East Technical University, Ankara, Turkey.

3. Egyptian Code for Soil Mechanics and Foundations (2001), "Part 7 - Retaining Structure".

4. German Geotechnical Society, (2008), "Recommendations for Excavation EAB", $2^{\text {nd }}$ Edition, Ernst \& Sohn, Berlin, English Translation.

5. O'Neill, M.W., and Reese, L.C., (1999), "Drilled Shafts: Construction Procedures and Design Methods", FHWA-IF-99-025, Fedral Highway Administraction, Washington, D.C., USA.

6. Salem, T.S., (1997), "Analysis of Offshore Piles", Ph. D. Thesis, Department of Structural Design, Zagazig University, Zagazig, Egypt. 